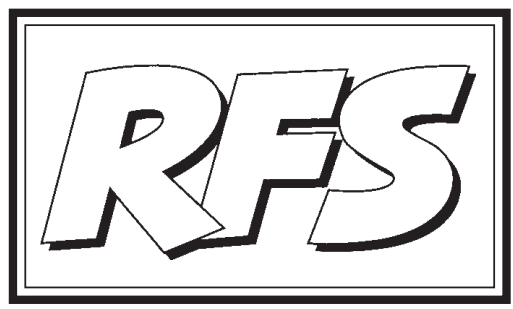

Revista de Fomento Social, 57 (2002), 509-531

\title{
Realidad social: oportunidades y retos para las instituciones universitarias de la Compañía de J esús
}

\section{Ildefonso CAMACHO LARAÑA*}

Para comprender el sentido y alcance de estas páginas es preciso tener en cuenta el contexto en que nacieron. Fueron preparadas como una ponencia para el Encuentro interuniversitario del profesorado de los centros superiores de la Compañía de J esús en España, que se celebró en Córdoba los días 11 y 12 de julio de 2002. Su objeto era ofrecer una panorámica de los grandes desafíos actuales, conectándolos con algunos rasgos específicos de estas instituciones universitarias de los jesuitas. Por esta razón resultaba imposible entrar en los detalles de cada uno de los temas seleccionados. Se me dispensará entonces de hacerlo también en este texto que ha sido escrito con posterioridad al encuentro.

* J esuita, profesor de Moral Social en la Facultad de Teología de Granada y de Ética en ETEA. 
Para hablar de retos me parece que hay que armonizar una doble perspectiva: por una parte, la del sujeto al que dichos retos interpelan, en este caso las instituciones universitarias y el personal que trabaja en ellas; por otra parte, los retos en sí, o grandes tendencias de nuestro mundo, que nos interpelan y nos invitan a reaccionar. Estos dos aspectos serán tratados respectivamente en las dos partes en que se ha dividido el texto.

$\mathrm{Ni}$ que decir tiene que todo esto se hará desde una perspectiva creyente. Por eso me parece útil comenzar citando un párrafo extraído de un documento sinodal de 1971, en el que se abordaba la función de la Iglesia en la lucha por la justicia. Dice así:

La situación actual del mundo, vista a la luz de la fe, nos invita a volver al núcleo mismo del mensaje cristiano, creando en nosotros la íntima conciencia de su verdadero sentido y de sus urgentes exigencias ${ }^{1}$.

Lo que aquí se nos está sugiriendo es que valoremos más el papel de la realidad como instrumento para comprender las exigencias de la fe. Porque el Evangelio no es un texto frío y atemporal, que pueda ser leído y entendido igualmente por cualquier persona desde cualquier cultura y en cualquier coyuntura histórica. El Evangelio resuena de forma distinta dependiendo del lugar desde donde se lee y de la sensibilidad humana con que uno se acerca a él. Nuestra esperanza es que la consideración de ciertos fenómenos dominantes del mundo de hoy nos permita descubrir mejor lo que el Evangelio exige de nosotros; más aún, que sea el único camino adecuado para ello.

\section{Desde donde nos acercamos a las oportunidades y a los retos}

Lo que se pretende en esta primera parte es exponer algunas orientaciones recientes de la Compañía de J esús para sus instituciones universitarias. EI P. General, Peter Hans Kolvenbach, ha dedicado recientemente algunas intervenciones significativas a esta cuestión, y va a ser en ellas donde voy a inspirarme. Pero, previamente, no parece superfluo recordar algunos aspectos de la espiritualidad ignaciana de perenne validez: me refiero al tema del discernimiento.

1 Sínodo Universal de Obispos 1971, La justicia en el mundo, parte II. 
1.1. Punto de partida: el discernimiento como actitud ignaciana hoy insustituible

Hablar del discernimiento merecería no ya un artículo, sino un libro entero. Mi pretensión es más modesta: sólo enumerar algunos puntos esenciales, sin entrar en más análisis de ellos, como pórtico para lo que sigue. Tales puntos podrían sintetizarse así:

a) El discernimiento no es más que la búsqueda concreta de la voluntad de Dios en cada momento. El cristiano no se rige en su vida sólo por normas o principios universales, sino que busca la respuesta concreta a cada situación en la que se encuentre, respuesta que no está predeterminada de forma unívoca y general. El discernimiento presupone, por tanto, la misión, que es el marco en que tales respuestas seintegran y encuentran su sentido. Los tres ingredientes del discernimiento son, pues: los principios generales, la misión y la situación concreta.

b) La historia reciente de la Compañía no se entiende sin el discernimiento, y no sólo personal, sino también comunitario. No puede interpretarse de otra manera el giro que la Compañía dio a raíz del concilio Vaticano II, en sus congregaciones generales 31 y, sobre todo, 32: fue entonces cuando redefinió su misión como "servicio de la fe y promoción de la justicia"2. La realidad del mundo en aquellos años y la conciencia de los nuevos retos del momento, la increencia y la injusticia, marcaron profundamente el Vaticano II. La Compañía de J esús, por su parte y como respuesta a la invitación del Concilio, entró en un proceso que no admite mejor designación que "discernimiento comunitario". Dicho proceso, no fácil ni desprovisto de obstáculos, no puededarse por terminado: quizás uno de las consecuencias más significativas de él es la conciencia de que, en un mundo tan cambiante, el discernimiento ha de ser, como nunca, una actitud permanente. Sin embargo, este discernimiento comunitario plantea una problemática que no es idéntica a la propia del discernimiento personal.

c) No puede ignorarse que las instituciones muestran una especial resistencia a someterse al discernimiento comunitario, que es el más adecuado para ellas. Esta resistencia es debida a su natural inercia y a la resistencia que de aquí deriva para el cambio. Esta circunstancia debeser muy tenida en cuenta cuando se trata de centros universitarios con larga historia y una tradición muy consolidada por los buenos resultados obtenidos en el pasado: esto

2 Congregación General 32 (1975), Decreto 4: Nuestra misión hoy: servicio de la fe y promoción de la justicia; Decreto 2: J esuitas hoy. 
incrementa la dificultad para comprender que el presente es distinto y exige nuevas actitudes y enfoques.

d) El P. Kolvenbach, cuando analiza en una carta de los comienzos de su generalato lo que ha de ser el discernimiento comunitario, sugiere para él algunas condiciones personales en aquellos que lo llevan a cabo: el crecimiento en libertad interior (sin verdadera libertad no hay discernimiento), la armonización de trabajo y reflexión (para no caer ni en el activismo irreflexivo, ni en análisis interminables que nunca desemboquen en decisiones y acción), la integración en la institución (si uno se considera ajeno a la institución, como "trabajador por cuenta ajena" en ella, es casi imposible que discierna con ella y sobre ella), el diálogo fraterno ( $p$ ara que las distintas sensibilidades y puntos de vista de los que intervienen en el discernimiento se enriquezcan mutuamente) ${ }^{3}$.

1.2. Algunas orientaciones recientes del $P$. Kolvenbach para las instituciones universitarias

Podríamos haber comenzado por la Congregación General 34, la última celebrada por los jesuitas, que dedicó un decreto específico a la educación universitaria. Nos bastará recordar de él su mensaje central: que una institución universitaria de la Compañía debe aspirar a armonizar los dos aspectos: ser universitaria (en cuanto a calidad y rigor) y ser jesuita (acorde con la misión de la Compañía de servicio de la fe y promoción de la justicia). Sin embargo, he preferido avanzar sobre esa propuesta y aprovechar tres intervenciones muy recientes del $P$. Kolvenbach sobre la misión de la Compañía en el mundo universitario: corresponden, sucesivamente a los años 2000, 2001 y 2002. No voy a hacer un estudio sistemático de cada uno de ellas, sino que me limitaré a extractar algunos puntos que me parecen relevantes (y mutuamente complementarios) en este momento.

a) En el marco de la misión de la Compañía y en coherencia con dicha misión ${ }^{4}$

Los días 5 a 8 de octubre de 2000, las veintiocho universidades y centros de estudios superiores de la Compañía de Jesús en los Estados Unidos

3 P. H. Kolvenbach (1986), Carta sobre el discernimiento apostólico en común, 5 noviembre 1986. Texto en: Acta Romana SJ 19/3, 712-713.

4 P. H. Kolvenbach, discurso en la Universidad de Santa Clara sobre "El servicio de la fe y la promoción de la justicia en la educación universitaria de la Compañía de J esús de Estados Unidos", 6 de octubre de 2000. Texto en Revista de Fomento Social 55 (2000), pp. 595-614. 
celebraron una Conferencia sobre "El compromiso por la justicia en la educación superior de la Compañía" en la Universidad de Santa Clara (California) para conmemorar el 250 aniversario del Decreto 4 de la Congregación General 32, y reflexionar sobre su impacto en el apostolado universitario de la Compañía en Estados Unidos. En este marco el P Kolvenbach pronunció un importante discurso.

En el centro de sus palabras está la idea, tomada de la Congregación General 34 y ya mencionada, de que las instituciones universitarias de la Compañía deben quedar marcadas por los rasgos de ésta, y concretamente por su misión: dichas instituciones son instrumentos al servicio de su misión. Esta tarea es la que asumen y hacen suya tanto los jesuitas como los laicos que trabajan en ellas. En palabras tomadas del discurso:

¿Qué es pues lo que constituye este carácter ideal [de un centro universitario de la Compañía]? ¿Y qué es lo que contribuye a su percepción pública? Tratándose de la universidad de la Compañía, este carácter tiene que ser la misión, que ha sido definida por la Congregación General 32 y reafirmada por la Congregación General 34: la diakonia fidei y la promoción de la justicia como el modo de proceder y de servir a la sociedad característicos de una universidad de la Compañía.

Y aludiendo a la última Congregación:

En palabras de la Congregación General 34, una universidad de la Compañía tiene que ser fiel, al mismo tiempo al sustantivo "universidad" y al adjetivo "jesuita". Por ser universidad se le pide dedicación a "la investigación, a la enseñanza y a los diversos servicios derivados de su misión cultural". El adjetivo "jesuita" requiere de la universidad armonía con las exigencias del servicio de la fe y promoción de la justicia establecidas por la Congregación General 32, Decreto 4.

Hasta aquí sólo se subrayan directrices anteriores. Pero Kolvenbach hace todavía el esfuerzo de concretar cómo se puede llevar esto a cabo. Se refiere en primer lugar a los estudiantes, y luego a los profesores. A estos últimos les propone:

Del mismo modo que los estudiantes tienen necesidad del pobre para aprender, los profesores necesitan compartir [su trabajo] con el apostolado social para investigar, enseñar y formar. Tales lazos no convierten a las universidades de la Compañía en sucursales de los ministerios sociales o en instancias de cambio social, como cierta retórica del pasado llevó a algunos a temer. Son, más bien, como una garantía verificable de la opción del profesorado y una ayuda real para, como se dice coloquialmente, jestar siempre en la brecha!

Me parece importante esta sugerencia porque busca sacar al docente universitario de la "torre de marfil" en que puede convertirse su profesión, dentro de la cual se aísle y casi se inmunice frente a la realidad de los 
problemas ${ }^{5}$. Se plantea aquí la difícil dialéctica entre cercanía y distancia. La cercanía es insustituible para mantener viva la sensibilidad ante los problemas, pero la distancia es necesaria para la objetivación y el análisis. Lo que se ofrece aquí es una vía concreta para que ambas dimensiones no se ignoren: si el profesor universitario corre el peligro de la distancia, se le sugiere ahora que utilice otra plataforma de la Compañía que le puede sacar de esa distancia, las instituciones de apostolado social. Se producirá entonces una simbiosis fecunda entre instituciones universitarias e instituciones sociales, ambas inspiradas por una misma misión que se realiza de modo diferente, pero complementario, en unas y otras.

Esta invitación busca también superar la separación entre distintas instituciones jesuitas, y facilitar la conciencia de que estar integrado en un centro universitario de la Compañía implica pertenecer a un cuerpo más amplio y compartir una misión común pero realizada de formas diversas.

b) En colaboración con los laicos, a los que se invita a una auténtica identificación con la misión ${ }^{6}$

Uno de los temas recurrentes en la Compañía de Jesús en las últimas décadas, que se aborda cada vez con una profundidad mayor, es el de la colaboración jesuitas-laicos. De nuevo la última Congregación General (de 1995) es referente obligado con su reenfoque del tema: del clásico "colaboración de los laicos" al nuevo "colaboración de los jesuitas con los laicos"7.

El P. Kolvenbach vuelve sobre este punto, para hacer algunas matizaciones sobre el alcance que una tal colaboración pueda tener. Son observacio-

5 Por eso recomienda el mismo Kolvenbach un poco más adelante: La investigación realizada por el profesorado, que "debe ser rigurosa en su racionalidad, firmemente enraizada en la fe y abierta al diálogo con todos los hombres de buena voluntad", no sólo ha de atenerse a los cánones de cada disciplina, sino adentrarse en lo más profundo de la realidad humana, para ayudar a hacer del mundo un lugar más habitable para los 6.000 millones que vivimos en él. Quiero dejar claro que todo el conocimiento que se adquiere en la universidad es valioso en sí mismo, pero es además un conocimiento que tiene que preguntarse a sí mismo, "en favor de quién y en favor de qué" está.

6 P.H. Kolvenbach, Alocución a la Reunión Internacional de la Educación Superior de la Compañía, sobre "La Universidad de la Compañía de J esús a la luz del carisma ignaciano", Roma 27 de mayo de 2001.

7 Congregación General 34 (1995), Decreto 13: Colaboración con los laicos en la misión. 
nes basadas, a la vez, en el realismo y en el respeto a la conciencia personal. Se huye de todo reduccionismo o de la tentación de convertir a los laicos colaboradores en unos como "mini-jesuitas":

Colaboración no significa siempre compromiso con la misión. Tenemos derecho a presuponer que los jesuitas se identifican con su misión, pero no podemos dar por sentado que todos los laicos se identifican con la misión propia de los jesuitas. Loslaicos no están llamados a ser mini-jesuitas, sino a vivir su propia vocación laical. Respetar el modo como el Señor conduce a cada persona es fundamental en la espiritualidad ignaciana. Esto no obstante, un colaborador de una institución de educación superior de la Compañía, de alguna manera debe identificarse con la misión institucional.

Lo que se hace en estas palabras es perfilar posibles formas de colaboración: desde la simple colaboración hasta una identificación plena con la misión de la Compañía. Lo que quedaría excluido sería la falta total de sintonía con la misión institucional; sólo así se podrá evitar situaciones de personas que trabajan en instituciones jesuitas, mientras que su corazón está muy lejos de los grandes objetivos que enmarcan el funcionamiento de éstas. Lo deseable, por tanto, es algún grado de identificación con dicha misión.

Esta observación tiene que ver con el peligro inherente de discriminación de los laicos según su grado de identificación o cercanía. Nada más lejos de la mentalidad de Ignacio. Pero ello no es obstáculo para hacer un ofrecimiento, para proponer un proyecto al que el laico se adhiera por voluntad propia, en la medida en que dicho proyecto responde a sus aspiraciones profesionales o humanas:

Por otra parte, sería odioso catalogar y discriminar al personal de acuerdo a su supuesto nivel de compromiso con la misión. En la misión de la Compañía, como en la casa del Señor, hay muchas moradas. Para Ignacio, no hay peor error en la vida espiritual que querer conducir a todos por el mismo camino. La misión de una institución de educación superior de la Compañía -igual que la fe- no se impone, sino que se propone. En una "cara a cara" de mutuo respeto y sinceridad, los colaboradores son invitados a compartir esta misión y hacerla propia, a distintos niveles.

Puede decirse que en estos pasajes que hemos entresacado del discurso de Roma el P. General busca un equilibrio entre el respeto a las personas y a la vocación particular de cada uno, por una parte, y la conveniencia de una integración afectiva en las instituciones, por otra. Ofrecer cauces para discernir el grado de identificación aceptable en cada caso y llenarlo de contenido en una de las tareas irrenunciables de toda institución de la Compañía de Jesús. 
c) Con actitudes y principios de acción que constituyen un contraste con ciertas tendencias de nuestro mundo ${ }^{8}$

La presencia de los jesuitas polacos en la educación tiene una larga historia, forzosamente interrumpida en los años del comunismo. Con la caída de éste, la Compañía en Polonia se apresta a recuperar esta dimensión de su misión. Es en este contexto donde hay que leer la más reciente intervención del P. Kolvenbach sobre el tema (20 mayo 2002), que tiene como objeto animar este proceso de reconstrucción. De su discurso extraemos tres actitudes, cuya validez es incontestable para cualquier proyecto universitario.

Como en otras ocasiones, también ahora comienza Kolvenbach remontándose a la tradición originaria de la Compañía y a las adaptaciones que se produjeron en los primeros tiempos. Es sabido que la dedicación a la educación se convirtió, ya en vida del fundador, en uno de los campos prioritarios de acción de los jesuitas. La experiencia personal de Ignacio -en los años que pasó, ya como adulto, en las universidades de Alcalá y París- fue decisiva para comprender el reto que suponía la nueva cultura que por entonces empezaba a respirarse en estos centros europeos del pensamiento. Por eso el proyecto educativo de la Compañía, que pronto se plasmaría en la Ratio studiorum, establecería como su columna vertebral la formación integral de la persona?.

Éste es el punto de partida de Kolvenbach en el discurso que ahora comentamos, convencido de que la importancia de ese enfoque inicial de la educación no es menor en nuestro tiempo. De ahí que la primera actitud que se recomienda para los que trabajan en estos centros es que no basta con adquirir conocimientos, hay que formar personas:

Reconociendo que el contexto de la vida intelectual en el siglo XVI, tal como San Ignacio y los primeros jesuitas lo conocieron, es muy diferente del nuestro, también ellos debieron experimentar la tensión entre adquirir conocimientos y ser formados. En el comienzo de los Ejercicios Espirituales, que reflejan la experiencia espiritual de Ignacio, leemos que lo que llena y satisface al alma no es el mucho saber, sino el

8 P. H. Kolvenbach, Discurso en la Escuela Universitaria de Filosofía y Educación "Ignatianum", sobre "La dimensión intelectual de los ministerios jesuitas", Cracovia, Polonia, 20 de mayo de 2002.

9 El texto de la Ratio studiorum y los documentos recientes que actualizan aquellas orientaciones pueden verse en E. GIL CoRIA (ed.) (1999), La pedagogía de los jesuitas ayer y hoy, Universidad Pontificia Comillas, Madrid. 
comprender las realidades profundamente y el saborearlas interiormente (Ejercicios 2). No deja de ser sorprendente que un texto que anima a una reflexión profunda sea crítico al mismo tiempo con el deseo de adquirir mucho conocimiento.

Kolvenbach subraya que esta preocupación clásica de la Compañía por la formación integral de la persona es hoy muy necesaria por dos razones. En primer lugar, ahora como en el tiempo de Ignacio, estamos asistiendo a una ruptura en el mundo del conocimiento. En segundo lugar, y aquí el paralelismo es menor con épocas pasadas, hoy abunda tanto la información que nos sentimos desbordados por ella. Las nuevas tecnologías de la información y de las comunicaciones, así como su enorme difusión, han producido una verdadera inundación, que nos hace más conscientes de la falta de una verdadera formación. Porque formar personas es mucho más que tener acceso a la información.

Una segunda actitud que Kolvenbach recomienda, muy en sintonía con la anterior, es la de una sana crítica ante nuestro mundo, unida a una verdadera libertad de espíritu:

Una sana actitud crítica ante el mundo que nos rodea forma también parte de la actividad intelectual. Debemos aprender a resistir a la indoctrinación y a las presiones externas, cualquiera que sea su origen. No debemos dejarnos influir en exceso por las corrientes de pensamiento más en boga. Y está también el mundo interior, con sus afanes más o menos sutiles por adquirir una posición y conseguir honores. Fue con libertad de espíritu como San Ignacio y sus primeros compañeros avanzaron en su formación intelectual, establecieron universidades y centros educativos, llevaron adelante la tarea apostólica y estimularon la dedicación al estudio. Fueron constructivamente críticos respecto al mundo intelectual de su tiempo.

Lo que ahora se nos está recomendando es una mezcla de espíritu crítico y libertad, quenos permita tomar distancia sobreun pensamiento que se deja llevar de la moda o de las últimas novedades. Un pensamiento riguroso y crítico que se distancie de todo eso exige una persona madura, que responda al modelo de formación integral propiciado más arriba. Y es propio de un sujeto así esa libertad de espíritu que nos ponga a salvo de la preocupación por "el último grito".

Todavía una tercera acti tud caracterizaría la tarea universitaria. Se pide una actividad intelectual, no centrada en sí mismo, sino motivada por el mejor servicio:

Hoy día, como en los tiempos de Ignacio, la actividad intelectual corre el riesgo de quedar centrada en sí misma, el estudio puede realizarse para el propio provecho y no por motivos de un mejor servicio. Ahora bien, en la mentalidad de Ignacio todo trabajo intelectual debe ordenarse al servicio de la humanidad, de todas las personas y de toda 
la persona. Debe estar arraigado en la realidad humana y en el respeto a la libertad de los otros, ya sea como colaboración o como confrontación.

A nuestra cultura contemporánea se la tacha de individualista y egocéntrica. Asumir como reto en la educación el fomento de actitudes abiertas a los otros y disponibles al servicio tiene al go de contracultural. Y esees, sin duda, la clave final de este discurso. Se trata de ofrecer un proyecto educativo diferente, no basado ni en la acumulación de conocimientos, ni la formación superespecializada, ni en las tendencias más de moda, ni en el provecho propio. Formación integral, espíritu crítico, libertad interior y servicio a los otros son las coordenadas del tipo de persona que se quiere promover. Todo ello resulta en perfecta coherencia con la misión apostólica de la Compañía tal como fue definida en los últimos tiempos y es muy apto para informar todas las tareas educativas.

\section{Cuáles son las oportunidades y los retos para nuestras instituciones}

Si al comienzo se indicaba que estas páginas no pretendían entrar en el análisis profundo de los temas que desfilarían por ellas, más urgente es repetir esa observación aquí. Hablar de los grandes retos de nuestro tiempo obliga a hacer una selección que, en cualquier caso, resultará subjetiva. Mi intención no es justificar cada uno de los retos que he seleccionado. Todos ellos me parecen suficientemente significativos, aunque cualquier lector podría añadir otros y suprimir algunos. Más que discutir la selección que he hecho, me propongo mostrar dos cosas: que estas grandes tendencias 0 hechos mayores de nuestro tiempo constituyen verdaderos retos para las instituciones universitarias de la Compañía de Jesús; y que la tradición educativa de la Compañía y las orientaciones más recientes ofrecen elementos para una respuesta adecuada a ellos.

\subsection{La globalización en sus distintas manifestaciones}

Una primera definición de la globalización puede ser ésta: la globalización es la presencia del mundo entero en nuestras vidas ${ }^{10}$. Tiene la ventaja de conectar un fenómeno a primera vista ajeno a la vida cotidiana de cada uno con lo que es nuestra experiencia de cada día. Pero es una definición

10 Commission Justice et Paix - France, Maîtriser la mondialisation (mars 1999), Documentation Catholique 81 (1999) 330. 
insuficiente. Es mejor distinguir las dimensiones económica, política y cultural de la globalización.

\title{
a) La globalización como fenómeno socioeconómico
}

Creo que la dimensión primaria de la globalización es la socioeconómica. Por eso es oportuno comenzar definiéndola. Desde este punto de vista la globalización es el proceso dinámico de creciente libertad e integración mundial de los mercados de trabajo, bienes, servicios, tecnología y capitales ${ }^{11}$. Ello significa, en último término, que el mercado nacional ha dejado su lugar al mercado mundial como referente fundamental de toda la actividad económica.

Son evidentes las ventajas de este proceso en términos: intercambios, ampliación, incremento de oportunidades, etc. Sin embargo, nos interesan más en este momento algunos efectos negativos que lo acompañan. El Programa de Naciones Unidas para el Desarrollo (PNUD) se ha encargado de poner de relieve los más destacados, de los que dejamos constancia escuetamente:

1) La globalización tiene carácter selectivo: no todo se liberaliza al mismo tiempo, sino en función de los intereses de los más fuertes (véase lo que pasa con productos agrícolas y textiles y con libre circulación de personas, y cómo su liberalización está controlada por los países más fuertes).

\begin{abstract}
Los principios de los mercados mundiales libres, sin embargo, se aplican de manera selectiva. Si así no fuera, el mercado mundial de mano de obra sin calificar sería tan libre como el mercado de las exportaciones o los capitales de los países industrializados. Las negociaciones mundiales avanzan rápidamente hacia un mercado mundial libre en inversiones y servicios extranjeros. Pero la intervención en la agricultura y los textiles sigue siendo elevada, lo que constituye un obstáculo para los países en desarrollo. Carentes de poder, con demasiada frecuencia se descuidan y socavan los intereses de los países pobres y de los pueblos pobres ${ }^{12}$.
\end{abstract}

2) La globalización produce desigualdades, pobreza y marginación. Otra cosa no se podría esperar cuando se deja actuar con creciente libertad al

11 G. de La Dehesa (2000), Comprender la globalización, Alianza, Madrid, 17. Véase también: CONSEJO de RedACCIÓN (2000), «Globalización integradora vs. globalización excluyente», Revista de Fomento Social 55, 143-160.

12 Programa de las Naciones Unidas para el Desarrollo (1997), Informe sobre desarrollo humano 1997, PNUD, Nueva York - Mundi-Prensa, Madrid, 92. 
mercado, poniendo en relación a personas, colectivos y países con grandes diferencias entre ellos ${ }^{13}$.

La globalización tiene ganadores y perdedores. Con la ampliación del comercio y la inversión extranjera, los países en desarrollo han visto profundizarse las diferencias entre ellos. Entretanto, en los países industrializados el desempleo ha subido a niveles que no se veían desde los años treinta, y la desigualdad del ingreso, a niveles que no se conocían desde el siglo pasado.

Se supone que una marea en ascenso levantará todos los botes. Pero algunos pueden navegar mejor que otros. Los yates y los transatlánticos de hecho se están elevando en respuesta a las nuevas oportunidades, pero las balsas y los botes de remo están haciendo agua, y algunos se están hundiendo rápidamente ${ }^{14}$.

3o) La globalización genera inestabilidad e inseguridad. Ulrich Beck ha reflexionado sobre esta nueva situación en una reciente pero conocida obra: La sociedad del riesgo ${ }^{15}$. El PNUD también lo denuncia:

La mundialización, una fuerza dominante en el último decenio del siglo XX, está dando forma a una nueva era de interacción entre los países, las economías y los pueblos. Está aumentando los contactos entre la gente por encima de las fronteras nacionales en materia de economía, tecnología, cultura y estructura de gobierno. Pero además está fragmentando los procesos de producción, los mercados de trabajo, las entidades políticas y las sociedades. De esta manera, si bien la mundialización tiene aspectos positivos, innovadores y dinámicos, tiene también aspectos negativos, perturbadores y marinantes ${ }^{16}$.

\section{Oportunidades y retos de la globalización socioeconómica}

1) Hacer de la globalización una oportunidad para todos. Si la globalización tiene ganadores y perdedores, la gran tarea consiste en procurar que los beneficios de la globalización lleguen a todos. Ésta ha sido la propuesta de un reciente documento promovido por las Conferencias Episcopales de la Unión Europea, cuyo título es precisamente éste ${ }^{17}$. El mundo universitario es un

13 Para un análisis del mercado, cuestión en la que no podemos entrar aquí, es valioso: L. DE SEBAStIÁn (1999), El rey desnudo. Cuatro verdades sobre el mercado, Trotta, Madrid.

14 Programa de las Naciones Unidas para el Desarrollo (1997), I.c.

15 U. Beck (1998), La sociedad del riesgo. Hacia una nueva modernidad, Paidós Ibérica, Barcelona

16 Programa de las Naciones Unidas para el Desarrollo (1999), Informe sobre desarrollo humano 1999. La mundialización con rostro humano, PNUD, Nueva York - Mundi-Prensa, Madrid, 25.

17 Global governance. Our responsability to make globalisation an opportunity for all. A report to the Bishops of COMECE, Bruselas, septiembre de 2001. Véase I. CAMACHO (2002), "Globalización 
lugar muy idóneo para trabajar en esta dirección. Son muchas las ocasiones que se ofrecen para ello en la investigación, si se sabe librar a ésta del yugo del pensamiento dominante, tanto en la selección de proyectos como en el enfoque que se déa los mismos. Y tendría que ser también una preocupación de la tarea docente el sensibilizar con rigor científico para no dejarnos llevar por una visión y una práctica que sólo se fije en las ventajas que la globalización encierra para los países más desarrollados.

2) Convertir la interdependencia en solidaridad. Me inspiro aquí en la afirmación de Juan Pablo II en su encíclica sobre el desarrollo: la mejor respuesta moral a la interdependencia creciente de nuestro mundo es la solidaridad, entendida ésta, no como un vago sentimiento, sino como la voluntad decidida de actuar todos como responsables de todos ${ }^{18}$. El gran riesgo del discurso actual sobre la solidaridad, tan en boga, es que ésta sea entendida sólo con una sentimiento superficial y pasajero. Para evitarlo es preciso poner a punto proyectos que hagan ver cómo es posible y deseable sentirnos "todos responsables de todos". Paradójicamente el mundo científico es reticente a ciertos conceptos que suenan a moralizantes y parecen remitir más a actitudes personales que a un análisis riguroso de las estructuras sociales. Algo de eso ocurre con la solidaridad. Por eso es un reto para nosotros mostrar que la solidaridad no es sólo una actitud individual, sino también un principio de organización social capaz de inspirar proyectos económicos y políticos: ¿no podría esto dar sentido a muchos esfuerzos de investigación y docencia en nuestras instituciones?

\section{b) La globalización como fenómeno político}

Sintéticamente, la globalización supone una nueva relación entre el mercado y el Estado: el Estado pierde protagonismo porque se diluye lo que es

y gobernabilidad: algunas propuestas recientes sobre la creación de un sistema de gobierno global", Proyección 49, 69-81.

18 El pasaje completo merece ser reproducido: Ante todo se trata de la interdependencia percibida como sistema determinante de relaciones en el mundo actual, en sus aspectos económico, cultural, político y religioso, y asumida como categoría moral. Cuando la interdependencia es reconocida así, su correspondiente respuesta, como actitud moral y social, y como "virtud", es la solidaridad. Esta no es, pues, un sentimiento superficial por los males de tantas personas, cercanas o lejanas. Al contrario, es la determinación firme y perseverante de empeñarse por el bien común; es decir, por el bien de todos y cada uno, para que todos seamos verdaderamente responsables de todos (J Uan PABLo II, Sollicitudo rei socialis, 38 ). 
su marco de actuación, las fronteras territoriales; al mercado se le reconoce su capacidad de garantizar la eficiencia económica, tras una etapa en que el Estado ha sido criticado por su ineficiencia.

Esto está acarreando dos consecuencias de relieve: a) una creciente amenaza para el Estado social, cuya viabilidad se encuentra frecuentemente cuestionada; b) un fuerte desarrollo de los procesos de integración supraestatal, como formas de fortalecimiento ante la globalización.

\section{Oportunidades y retos de la globalización política}

1) Contribuir a verdaderos procesos de integración regional. El discurso sobre la integración está hoy muy cargado de ambigüedades. Es frecuente que sólo se entienda como liberalización de mercados, como reflejo de esa exaltación del mercado tan difundida en nuestros días. Corregir esta visión es un importante reto para nuestras instituciones universitarias, haciendo comprender que la ampliación de los mecanismos de mercado sólo es aceptable si va acompañada de otros dispositivos que contrarresten la tendencia de aquellos a incrementar las diferencias entre las partes. Purificar y precisar el concepto de integración y concretar cuáles han de ser estos dispositivos correctores es una tarea urgente cuando tanto se insiste en los "tratados de libre comercio" y otras iniciativas semejantes.

2) Construir un sistema de gobierno mundial. Éste es un tema nuevo, del que se habla con insistencia desde las crisis en los mercados financieros internacionales a partir de 1994. Ellas parecen llevar a un cierto consenso sobre la necesidad de establecer algunas reglas del juego que controlen y dificulten esos movimientos tan irracionales y desproporcionados de los capitales. No es tan claro, en cambio, concretar cuáles sean las instancias que habrían de asumir esa función de poner cierto orden en la economía mundial $y$ en todo el orden internacional. Se habla de reformar y potenciar las Naciones Unidas, con tal de que previamente se asuma la difícil tarea de recuperar su credibilidad. Se habla también de una mayor cooperación entre los gobiernos, sobre todo aquellos más poderosos. Y se habla, por fin, de un fortalecimiento de la sociedad civil mundial ${ }^{19}$. El carácter universal de la Compañía de J esús y la extensa red de instituciones universitarias y sociales de que es titular son oportunidades irreemplazables para trabajar en estas

19 Sobre todo esto se puede ver la bibliografía citada en la nota 17. 
direcciones: las iniciativas que pudieran adoptarse en al gunos desus centros tendrían la posibilidad de ser potenciados si se refuerza el trabajo en red de todos ellos.

\section{c) La globalización cultural}

Como punto de partida hay que reconocer que las crecientes facilidades para las comunicaciones y la transmisión de información propician un intercambio cultural muy superior al de cualquier tiempo pasado. Pero deahí se siguen dos fenómenos simultáneos y, a primera vista, paradójicos.

Por una parte se refuerza el proceso de homogeneización cultural, que extiende los paradigmas de la cultura occidental, y especialmente la norteamericana. Los medios de comunicación (y los poderes que los sustentan) juegan aquí un papel decisivo. Esta cultura que se impone está muy marcada por los conceptos y valores de la tradición occidental, que tanto han contribuido a la civilización moderna: mencionemos entre ellos el valor de la persona y sus consecuencias (derechos humanos, democracia política), pero también los de un carácter más económico (primacía de los valores económicos y materiales y de los intereses individuales). No todos son igualmente positivos, ni han contribuido por igual al progreso de la humanidad. ¿Cabría decir que hoy sobresalen más aquellos más problemáticos, que subrayan, más allá de los límites tolerables, el individualismo y el materialismo?

En contraste con esa homogeneización cultural asistimos también a un creciente multiculturalismo, como coexistencia estable (más estable que en tiempos pasados) de diferentes culturas. Este proceso, que puede ser interpretado como una forma más evolucionada del pluralismo típico de las sociedades modernas, es para muchos expresión de una verdadera amenaza para la identidad cultural: por eso suscita reacciones a veces violentas. En todo caso el hecho reviste algunas peculiaridades que no se pueden ignorar: las distintas culturas conviven de forma estable, gracias al fenómeno de las migraciones, cada vez más permanentes y naturales en un mundo globalizado; esta convivencia estable hace a las culturas más iguales entre ellas y se traduce en reivindicaciones nunca hasta ahora conocidas de las culturas minoritarias; todo ello plantea exigencias nuevas sobre el respeto a las culturas y exige superar las fórmulas clásicas de la asimilación o el apartheid. 
524 REALIDAD SOCIAL: OPORTUNIDADES Y RETOS PARA LAS INSTITUCIONES UNIVERSITARIAS DE LA...

\section{Oportunidades y retos de la globalización cultural}

1) Ayudar a una tolerancia positiva entre las culturas. El concepto de tolerancia entendida casi como indiferencia ante "el otro" e ignorancia respecto a él (tolerancia negativa) se muestra hoy insuficiente. Contribuye a un aislamiento que favorece la construcción de estereotipos de ese "otro", cuyo desconocimiento genera sentimientos de desconfianza y miedo. La tolerancia positiva, que no es relativismo cultural, implica el interés por el otro y el deseo de conocerlo. Parte del supuesto de que todos tenemos algo que aprender de los demás, por muy distintos que sean culturalmente. Esta tolerancia positiva exige personas maduras, capaces de convivir en la diferencia y no sentirse amenazadas por ésta: en síntesis, todo lo que implica una verdadera formación integral, como la que se propone a nuestras instituciones universitarias.

2) Contribuir a una verdadera integración intercultural. El término "multiculturalismo", que hace unos años servía para designar una convivencia pacífica entre distintas culturas, tiende a ser sustituido hoy por "interculturalidad". No es banal el cambio terminológico. Se quiere subrayar con ello que no basta con garantizar la coexistencia, sino que hay que avanzar en la búsqueda de espacios comunes para esa convivencia, que no lo cifre todo en las diferencias, sino que busque también los puntos de encuentro y coincidencia. Casi podríamos hablar de una "transcultura", que nunca se confundiría con una cultura uniforme ni con la integración de todos en una única cultura. También aquí, tanto la formación integral de la persona como la interrelación que ofrece la red universitaria de la Compañía son bazas decisivas para este trabajo en favor de la interculturalidad.

\subsection{El neoliberalismo en el marco de globalización}

Hemos hablado ya suficientemente de globalización. El neoliberalismo tiene una estrecha relación con ella. Podríamos decir que es la ideología que mejor le cuadra. Le sirve de justificación.

El neoliberalismo ha podido difundirse con tanto éxito en estos años porque ha encontrado el terreno abonado en las deficiencias del modelo mixto de economía, ya sea en su versión del Estado social ya en otras. Los autores neoliberales han sido agudos en denunciarlas y drásticos en proponer remedios. El resultado ha sido una crítica despiadada del Estado y una correlativa exaltación sin reparos del mercado y de todo lo que sea liberali- 
zación. En este sentido, la globalización (versión planetaria de la economía de mercado pura) se convierte en ideal.

Para hacer una crítica del neoliberalismo es preciso comenzar indicando que los autores que se integran en esta corriente van mucho más allá que los liberales clásicos, a los que suelen invocar con entusiasmo. Ésta es una cuestión que merecería una mayor atención. Me limito a indicar dos líneas que podrían orientar la crítica del neoliberalismo hoy, según se atienda a sus aspectos económico o antropológico ${ }^{20}$.

Desdeel punto de vista de la ética económica es criticable la exaltación del mercado. Aceptemos que el sistema de mercado es el más eficaz para asignar los recursos y aumentar la producción, siempre y cuando se cumplan las estrictas condiciones que el modelo exige. Pero no es tan eficaz para la distribución, sobre todo cuando falta la igualdad entre los agentes económicos. Es más, la competencia, en este escenario de desigualdad, deja de ser colaboración y garantía para todos y se convierte en antagonismo y lucha a muerte por destruir al otro. Más aún, ni siquiera el mercado ideal de la absoluta transparencia funciona, al menos en dos casos: cuando la demanda no va acompañada de capacidad de pago (cuando la demanda no es solvente) y cuando se trata de bienes públicos (no susceptibles de apropiación excluyente). Todas estas limitaciones obligan a no caer en ningún tipo de exaltación desmesurada del mercado. La persistencia de la pobreza y su aumento en algunas regiones del mundo o el preocupante deterioro medioambiental son fenómenos que tienen no poco que ver con este entusiasmo por el mercado.

Cuando nos acercamos al neoliberalismo desde el punto de vista de la antropología es cuando mejor se percibe cómo se desborda con mucho el pensamiento de los liberales clásicos. Porque se produce una visión economicista del ser humano, que colorea el individualismo liberal tradicional. En efecto, el sistema de mercado facilita la implantación de un determinado sistema de valores, que lo legitima y le da consistencia: todo él se articula sobre la base de la competitividad y de una concepción materialista y economicista de la vida. Esta exaltación de la competitividad como valor significa que lo que la sociedad aprecia es aquella persona que está en condiciones de competir y el que en esa lucha diaria con los otros sabe imponerse. El otro queda reducido así, al menos potencialmente, a enemigo.

20 Cf. I. СамаCHo (1998), "Diez preguntas sobre el neoliberalismo”, Almogaren n. 23, diciembre, 45-76. 
Se da entonces como una absolutización del mercado y de su lógica (lógica de la equivalencia), que termina imponiéndose a todos los ámbitos de la vida humana y social. Sería interesante ahondar en estas cuestiones, pero es imposible hacerlo aquí.

\section{Oportunidades y retos ante el neoliberalismo}

1) Contribuir a un diálogo crítico con el neoliberalismo. Las consideraciones críticas esbozadas no son más que algunas sugerencias para indicar por dónde podría ir una diálogo a fondo con el neoliberalismo. Las ideas -y, muchas veces, las recetas- neoliberales están tan difundidas que no es raro oírlas repetir casi mecánicamente. Una tarea universitaria rigurosa no debe dejarse llevar imperceptiblemente por estas corrientes de moda. Pero también conviene huir de una cierta "demonización" del neoliberalismo, igualmente impropia de un pensamiento crítico, como si todo en él fuese igualmente desechable. Sólo un diálogo sereno, renuente a los tópicos, atento a la realidad y obsesionado con la verdadera justicia puede ser válido en este terreno.

2) Ver el mundo desde la perspectiva de los pobres. Esto último tiene su complemento en algo para lo que la misión de la Compañía ofrece recursos de valor indiscutible. Porque sabemos que la lucha por un mundo más justo no es sólo cuestión de conocimientos, sino que exige también cultivar una determinada sensibilidad: es lo que calificamos como "ver el mundo desde la perspectiva de los pobres", desde "el otro lado de la realidad", el contrario a aquel donde suele situarse quien vive en un mundo de abundancia y de bienestar. La cultura universitaria, y su forma de entender la neutralidad científica, no suele ser proclive a entrar en esta dinámica. Y, sin embargo, cuando el saber científico se pone al servicio de la causa de los pobres, jcuán sorprendentes y valiosos son sus resultados! Y se hace, en cierto sentido, contracultural.

\subsection{La crisis del Estado social}

Para nosotros, en Europa, la crisis del Estado social es uno de los fenómenos más significativos de los últimos tiempos. Algunos lo han achacado a la globalización y a la extrema competencia en mercados cada vez más integrados que ésta conlleva. Sin negar la verdad de esto, hay que ampliar las

\section{RFS}


perspectivas y fijar la atención también en las disfunciones que el propio modelo ha creado.

Resumiendo mucho estas disfunciones que el desarrollo del Estado social ha generado en nuestros países, cabría decir que estas sociedades mantienen su ritmo de demanda de prestaciones al Estado mientras que se resisten cada vez con más fuerza a que aumente la presión fiscal. La razón de esta paradoja puede estar en el reciente empeoramiento de las condiciones económicas generales. Esta crisis ha exigido al Estado nuevas intervenciones al tiempo que reducía sus ingresos. La crisis del Estado fiscal (con el consiguiente déficit público) se une a la conciencia de que en ese Estado crecen en paralelo sus dimensiones y su ineficiencia. El Estado ya no hace tan bien como antes lo que la sociedad espera de él, y esto le lleva a una cierta pérdida de legitimidad política, que aumenta al constatar que, además, se está convirtiendo en un instrumento al servicio de grupos (Estado patrimonialista) y en un reducto para la corrupción. Por debajo de todos estos procesos de deterioro se adivina una dinámica de fondo que podría expresarse así: en última instancia, el Estado social no hace sino institucionalizar la solidaridad, o crear unos mecanismos que permitan hacer frente a ciertas necesidades de todos con recursos de todos; ahora bien, este modelo deja de ser viable cuando la solidaridad como valor social se resquebraja. ¿Y no es este resquebrajamiento de la solidaridad como valor social lo que hace inviable un modelo que tendría ahí precisamente su base legitimadora?

A todo ello se une otro fenómeno que no está del todo desconectado de esa crisis del Estado social: la crisis del empleo y la crisis del trabajo. La nueva división del trabajo, que acarreó la crisis de los 70, produjo en los países industrializados un desempleo de carácter estructural y aceleró la difusión de las nuevas tecnologías de la información y las comunicaciones. Hoy el mercado de trabajo se ha adaptado ya a estas nuevas tecnologías en lo que al desempleo se refiere gracias a una redistribución del trabajo y al desplazamiento de éste desde unos sectores a otros. Pero ha tenido otro efecto crucial: ha transformado en profundidad la naturaleza del trabajo y la organización de la producción. Porque las nuevas tecnologías, no sólo contribuyen a hacer desaparecer todas las tareas repetitivas de rutina, sino que cuestionan la forma tradicional de trabajo, tan característica de la etapa industrial: el pleno empleo (empleo a tiempo completo, en tareas ocupacionales bien definidas y en un modelo de carrera profesional a lo largo del ciclo vital). 


\section{Oportunidades y retos ante la crisis del Estado social}

1) Ser creativos y no buscar las soluciones en el pasado. El Estado social fue una conquista de la que muchos países se enorgullecieron y siguen enorgulleciéndose. Pero las nuevas condiciones no permiten ya mantener tal cual el modelo, aunque tampoco cabe renunciar a sus principales logros. Buscar soluciones a esta situación exige no aferrarse al pasado, sino discernir lo que se puede mantener con creatividad e imaginación. Y nada tan acorde con el quehacer científico como la investigación de lo nuevo, la búsqueda paciente de soluciones que rompan con ciertos moldes o inercias del pasado. Es cierto que estas soluciones tienen que traducirse ulteriormente en programas políticos, pero estos necesitan muchaindagación previa que el político en activo no está en condiciones de realizar. Por otra parte, estas actitudes de creatividad e imaginación son tan esenciales a un ser humano que quiera ser responsable, que habrán de ocupar un lugar preeminente entre los valores que un centro universitario se propone promover en sus alumnos.

2) Promover el desarrollo de la sociedad civil. Es un tema hoy recurrente, que deriva de una experiencia: la de que la sociedad ha estado demasiado ausente, recluida en el mundo de lo privado y confiada en que el mercado es capaz de resolverlo todo con la ayuda del Estado. La crisis de este modelo basado en un cierto equilibrio (siempreinestable) entre mercado y Estado está propiciando la exigencia de una sociedad civil más activa. Ahora bien, esta sociedad civil ha de tener, entre sus actores primarios, al mundo del pensamiento y de la ciencia. La presencia de la universidad en la sociedad y en los grandes procesos que orientan el futuro es cada vez más valorada y deseada. Por otra parte, crear en el estudiante univer sitario la conciencia de su responsabilidad de ciudadano está entre los objetivos prioritarios de todo proyecto educativo que quiera responder a las necesidades específicas de hoy.

\subsection{La religión a la búsqueda de su nuevo lugar en la sociedad}

Decir que en nuestras sociedades avanzadas las religiones están desapareciendo del espacio público no es suficiente para describir todo lo que está pasando. El fenómeno es más complejo y requiere muchos matices ${ }^{21}$. Por

21 Cf. J. M. Mardones (1995), Para comprender las nuevas formas de la religión, Verbo Divino, Estella (Navarra), 179-181. 
una parte, asistimos a una cierta desestructuración o desinstitucionalización de la religión cristiana, como ponen de relieve las encuestas, que se manifiesta, a la vez, en una flexibilización doctrinal y en un aumento de la increencia. Pero, al mismo tiempo, se da una sugestiva presencia de lo sagrado en el ámbito de lo secular: es notoria la sacralización en el ámbito de la política y de sus representaciones, en las manifestaciones de la música y el deporte, del cuidado, mantenimiento y disfrute del cuerpo, de las relaciones con la naturaleza. Se observa también un renacer de lo místico, con un marcado carácter ecléctico: sobre la base de la tradición cristiana se introducen referencias orientales, pararreligiosas o psicológicas, que constituyen el entramado de muchos de esos nuevos movimientos religiosos tan en boga hoy. Y no falta, por fin, un cierto reencantamiento de la vida cotidiana con referencias frecuentes a lo oscuro del destino, la suerte, lo sorprendente e inexplicable: es esa religiosidad de tono menor que se mueve en torno al horóscopo, el gusto por las apariciones y la afición a consultar adivinos y lectores de cartas o esferas de cuarzo.

Ante este universo tan complejo la Iglesia como religión institucionalizada, a la que se le niega la relevancia pública de que disfrutó hasta no hace mucho tiempo, reacciona de forma defensiva, recluyéndose en sí misma, con una casi obsesión por la tradición, la salvaguarda íntegra de la fe y la seguridad de sus miembros. Probablemente esto reduce la autoridad moral de sus líderes, al menos ante extensas capas de la sociedad, aunque produce un mal contenido entusiasmo en los sectores más adictos y deja en un llamativo aislamiento a quienes buscan el diálogo con la modernidad en todas sus formas.

\section{Oportunidades y retos ante la evolución de lo religioso}

1) Formación personalizada e integral. Si la apuesta por una formación personalizada es uno de los rasgos más constantes de la tradición educativa ignaciana, hoy resulta más necesario que nunca volver a insistir en ello. Es explicable que este pluralismo ideológico y cosmovisional de nuestro mundo provoque miedo e inseguridad y lleve al aislamiento y a la intolerancia como refugio. Sólo una formación personalizada, que busque la verdadera seguridad humana ante todo en las propias convicciones, es capaz de hacer frente de forma madura a esta situación tantas veces incómoda. Por otra parte, esa formación no puede desentenderse de tantas interpelaciones como la mentalidad moderna lanza a la fe: sólo una formación integral permite que la fe no 
resulte una especie de "postizo" para el hombre de nuestro tiempo.

2) Diálogo con la cultura moderna desde el diálogo interreligioso. Pero el único rasgo del pluralismo no es la diversidad de cosmovisiones. Hay que contar también con los conflictos de nuestro mundo que tantas víctimas dejan en el camino. A este respecto, las grandes religiones históricas tienen un reto, que es tanto más apremiante cuanto mayor ha sido la tendencia histórica a subrayar las diferencias entre ellas y a traducirlas en enfrentamientos. ¿No ha llegado el momento de reconocer que ese patrimonio común, que es la fe en un Dios único (la fe monoteísta), es una excelente base para luchar por un mundo en que sea respetado el ser humano como reflejo de ese Dios único? El monoteísmo deja su impronta inconfundible en las diferentes antropologías de esas grandes religiones. Por consiguiente no se trata de dejarse llevar de un eclecticismo pragmatista, sino de ahondar en las raíces comunes de todos para promover la causa de Dios sobre el mundo y el ser humano.

3) Una Iglesia que sabe soportar la inseguridad y buscar desde ésta. Esta cierta inseguridad que deriva del pluralismo ambiente debe ser asumida, nunca (artificialmente) negada. La fe no elimina la inseguridad; más bien ofrece motivaciones y recursos para afrontarla. ¿No tenemos a veces la impresión de que la Iglesia se siente incómoda ante esa falta de certidumbres y busca soluciones que parecen ignorar la complejidad de lo real o los problemas y perplejidades del saber científico? La ciencia -y la universidad aspira a ser un espacio privilegiado para el desarrollo de ésta- es, por naturaleza, consciente de la provisionalidad de sus conocimientos y modesta en sus conclusiones: el científico, aunque a veces caiga también en la tentación de absolutizar su saber, está obligado a ser irremediablemente humilde. Y la Iglesia y sus instituciones harían un enorme servicio a la humanidad recordando al mundo científico los límites de su saber y adoptando una postura de diálogo y búsqueda: siempre serán preferibles posturas así a la de contraponer unas certezas (a veces incluso intentar imponerlas) al científico, que éste en modo alguno puede admitir.

4) Universalismo cristiano y tolerancia en un mundo globalizado. Por último un dato determinante del cristianismo en sus orígenes fue su universalismo. Una comunidad que nació muy vinculada a la tradición judía y al pueblo de Israel pronto se vio interpelada por el encargo de Jesús de "predicar el Evangelio a todas las naciones". El conflicto entre Pedro y Pablo a este respecto es bien conocido. ¿No hay que tomar conciencia del valor y 
la actualidad de ese universalismo en un mundo tan plural y tan interdependiente? Nunca como hoy se le ofrece al cristianismo una oportunidad tan clara de ser vínculo de unión entre culturas diferentes. Pero eso exige un esfuerzo renovado por educar en la tolerancia positiva, en la capacidad para el diálogo: todo ello no es sino la esencia misma de una formación verdaderamente integral.

\section{Conclusión}

Releyendo lo escrito tengo la impresión de haber dejado de lado cuestiones de enorme trascendencia (el desarrollo de la biología y las posibilidades de la manipulación genética, las nuevas tecnologías y sus efectos sobre la cultura y la sociedad, etc.) o de haber pasado demasiado rápidamente por otras, enormemente complejas y delicadas, que están sometidas a una amplia discusión. Si ésa es también la impresión del lector, ello debeiera ser un estímulo para volver sobre dichas cuestiones. Al fin y al cabo, era objetivo de estas páginas no el análisis detallado de algunos temas de nuestro tiempo, sino ofrecer una visión panorámica de los más importantes y presentarlos como retos para las instituciones universitarias de la Compañía de Jesús.

Todo lo dicho puede servir para comprender que la misión de la Compañía hoy y las recientes orientaciones de quienes tienen en ella la máxima responsabilidad son una base muy propicia, no sólo para no desentenderse de esos grandes temas, sino especialmente para convertirlos en objeto permanente de estudio e investigación, de compromiso personal einstitucional. Sirvan estas páginas, con todas sus limitaciones, como una invitación para seguir caminando... 